\title{
A Challenging Case of Sertraline - Induced Bruxism
}

\section{Sultan Albrahim, Yahia Albobali" and Marwa Elzain}

Psychiatry department at Hamad Medical Corporation, Doha Qatar

YahiaAlbobali, Psychiatry department at Hamad Medical Corporation, Doha Qatar

*Corresponding author: Yahia Albobali, MD, Psychiatry department at Hamad Medical Corporation, Doha Qatar

Received date: 17 August 2020; Accepted date: 24 August 2020; Published date: 28 August 2020

Citation: Albrahim S, Albobali Y, Elzain M (2020) A Challenging Case of Sertraline - Induced Bruxism. J Med Case Rep Case Series 1(2): https://doi.org/10.38207/jmcrcs20201036

Copyright: (C) 2020 Albobali Y. This is an open-access article distributed under the terms of the Creative Commons Attribution License, which Permits unrestricted use, distribution, and reproduction in any medium, provided the original author and source are credited.

Abstract
We describe a case of sertraline-induced bruxism. Different medications were tried to manage bruxism, including buspirone,
gabapentin, quetiapine, and clonazepam. Quetiapine gave the best result in treating bruxism in our patient, but its side effects, mainly
weight gain, were intolerable. Bruxism was resolved by stopping sertraline and switching to escitalopram.

\section{Introduction}

Selective serotonin reuptake inhibitors (SSRIs) are the most common medications used to treat the major depressive disorder. The work by targeting the serotonin transporter (SERT), which leads to higher extracellular levels of serotonin, which is considered the basis of their mechanism of action, although other mechanisms havebeen proposed [1]. SSRIs are generally safe and well-tolerated. However, side effects have been reported in relation to the use of SSRIs.Gastrointestinal side effects, sexual dysfunction, weight gain, dry mouth, and bleeding are among the side effects related to SSRIs [2]. They also have some side effects on the central nervous system including akathisia, tremor, dystonia, and bruxism [3-6].

Bruxism is an umbrella term under which fall different motor

\section{Case Report}

A 42-year-old man presented with a major depressive episode. The patient presented to our general adult psychiatry outpatient clinic with 3 months' history of mood symptoms including low mood, anhedonia, insomnia, anxiety, loss of energy, decreased appetite and significant weight loss ( $25 \mathrm{~kg}$ over 2 months). He reported a history of situational panic attacks, crying spells, feelings of helplessness and hopelessness, and recurrent thoughts of death. Symptoms had significantly worsened over the two weeks prior to presentation to the extent that he stopped going to work and became socially isolated. Symptoms were preceded by significant psychosocial stressors including a difficult divorce and an ongoing child custody court case. The patient had to take care of his three kids by himself which imposed a great burden on him.

He had no active suicidal or homicidal thoughts, intent, or plan. No history of suicide attempts or self-injurious behavior. No history of psychotic features. No history of manic episodes. No history of alcohol, cannabis, or illicit substance use. He smokes one pack of nicotine per day for many years. activities of the jaw muscles, including clenching or grinding of the teeth and thrusting of the mandible [7]. To explain SSRI-induced bruxism, it has been hypothesized that increased serotonergic action on the mesocortical neurons arising from the ventral tegmental area causes a dopaminergic deficit, leading to bruxism [8]. Trials have been conducted to reduce these side effects. Some studies attempted to determine the effect of certain medications on ameliorating bruxism and jaw dystonia. These medications include buspirone [910], aripiprazole [11], quetiapine [12], trazodone [13], clonazepam [14] gabapentin [15-17] and clonidine [18]. We report acase of bruxism caused by sertraline which responded best to a low dose of quetiapine compared to buspirone, gabapentin, and clonazepam trials.

The patient has a past psychiatric history of two episodes of major depressive disorder over the previous 13 years. The last episode was 5 years prior to this presentation where he improved on a short course of antidepressant (mirtazapine) and cognitive behavioral therapy. He lost to follow up with mental health services because he was subjectively doing well for the few years prior to presentation. $\mathrm{He}$ reported significant weight gain with mirtazapine in the past and was thus reluctant to reinstate it.

The patient had a history of sleeve gastrectomy 4-5 years ago without any major complications. He has a history of relapsing- remitting multiple sclerosis, diagnosed 14 years ago, had two attacks, received disease-modifying medications, and has had no relapses for the past 13 years. He had a normal neurological exam, no disability in any functional system with a score of 0 on the Expanded Disability Status Scale (EDSS). Even though there was noclinical change compared to before, a repeat MRI scan showed a new lesion in the spinal cord so Teriflunomide was started by his neurologist, but he was not adherent to it. The full physical examination was unremarkable. 
He has a family history of diabetes mellitus, hypertension, and drug addiction. He had had steady employment in the city where he presented for more than 20 years.

The patient was prescribed sertraline, started at a dose of $25 \mathrm{mg}$ once daily and titrated gradually up to $200 \mathrm{mg}$ over a 3 months' duration. He achieved full remission of his mood and anxiety symptoms after one month of starting him on the $200 \mathrm{mg}$ dose.

Initially, he tolerated sertraline very well. However, he started complaining of sleep bruxism 2-3 weeks after taking the $200 \mathrm{mg}$ dose, and his bruxism was worsening with time as he was grinding his teeth all day and during sleep. He had tooth pain every morning due to the severe clenching. He was not taking any other regular medications at this time. A mouth guard was not available. Sertraline dose was decreased to $150 \mathrm{mg}$ daily. Buspirone was added to mitigate the bruxism, and the dose was titrated gradually from $5 \mathrm{mg}$ twice daily to $20 \mathrm{mg}$ twice daily (total dose of $40 \mathrm{mg}$ ) for 4 weeks. He reported partial improvement; however, he remained with severe bruxism to the point that he brokeone of his teeth so the Buspirone trial was discontinued. A one-week trial of gabapentin $300 \mathrm{mg}$ daily was started. However, the patient reported no difference at all.

A trial of quetiapine immediate release (IR) $25 \mathrm{mg}$ twice daily was started and the patient reported significant improvement after the first dose and complete resolution of bruxism after 3 days. However,he started to complain of excessive sedation, constipation, increased appetite and sugar craving after one week. He was switched to quetiapine extended release (XR) $50 \mathrm{mg}$ once at bedtime to minimize the adverse effects, especially sedation. The patient reported less

\section{Discussion}

Drug-associated bruxism can have grave consequences on the dental and facial health of patients. This can include teeth destruction, malfunction of the temporomandibular joint, facial muscle contraction, and associated headache [1]. Although bruxism is not a common side effect of antidepressants, physicians should be aware of it due to its severe consequences. The common strategies for treatment are dose modification, medication discontinuation, or adding another agent to manage bruxism [19].

Bruxism in our patient showed a temporal relationship with the use of sertraline, starting after the initiation of sertraline and subsiding when the patient decided to stop it and reappearing again when the medication was started again during treatment. Naranjo Drug reaction probability scale was 7 , which is interpreted as a probable adverse drug reaction.

A very important point to discuss in the case of our patient is whether the bruxism is related to multiple sclerosis or not. In their study, Sevimet al. [20] reported three patients with moderate-to-severe bruxism occurring after multiple sclerosis exacerbations. These patients had not previously been diagnosed with bruxism, suggesting that this condition could be due to the cortico-basal gangliathalamocortical pathways affected in some MS episodes, possibly sedative effect and less constipation. He noted that sleep bruxism had resolved, reported that the effect was noticeable soon after taking the quetiapine XR at bedtime and reported less tooth pain in the morning, however, he complained of bruxism during the day. He reported sugar craving, became concerned about his weight gain and he expressed his wish to try another medication,so the quetiapine trial was discontinued. He lost $2 \mathrm{~kg}$ over the week following quetiapine discontinuation. Sertraline dose was decreased further to $100 \mathrm{mg}$ once daily and a two-week trial of clonazepam $0.5 \mathrm{mg}$ at bedtime started. The Patient complained of waxing and waning bruxism during the day and throughout the night. His dentist prescribed him Chlorzoxazone (muscle relaxant). However, both agents were discontinued as they were not helpful.

His anxiety and mood symptoms were worsening, and he started to have more anxiety attacks, so sertraline was switched to escitalopram over one week. Sertraline dose was decreased to $50 \mathrm{mg}$ daily then discontinued and escitalopram commenced at $10 \mathrm{mg}$ once daily and then increased to $20 \mathrm{mg}$ once daily which worsened his bruxism. Escitalopram had to be gradually stopped and during this period the patient has engaged again with psychotherapy and started cognitive behavioral therapy sessions. His bruxism went away shortly after the medication was stopped. Upon follow up the patient showed marked improvement in his depressive symptoms, in part because of cognitive behavioral therapy, and also due to the resolution of his social problems (the divorce and child custody case) which lifted huge stress off the patient's shoulders.

leading to bruxism. Another study [21] has shown that bruxism is encountered more often in patients with MS, compared with the normal population, and can be associated with the patients' age level and EDSS scores. In our patient's case, however, the fact that he did not have other neurological defects, and the temporal relationship of the bruxism to the antidepressant and its resolution after stopping the medication favors the SSRI-induced bruxism hypothesis. The patient's neurologist prescribed him Teriflunomide on the basis of his newly found lesion on MRI but the patient was not compliant to this medication, so it is unlikely that it had any effect on the bruxism.

Most of the case reports with sertraline induced bruxism were managed by buspirone [19]. Buspirone was tried as an attempt to relieve our patient's bruxism. Improvement related to buspirone has been explained by its dopaminergic action on the mesocortical pathway [4]. Unfortunately, our patient has minimal relief with buspirone.

We found a similar case in which buspirone did not help but there was a positive response to Gabapentin [19]. The first report to show that gabapentin is potentially effective in the treatment of antidepressantinduced bruxism was done by Broun and Hong in which bruxism was associated with venlafaxine [15]. Unfortunately,our patient did not 
get any relief with Gabapentin. The use of clonazepam has been studied and was reported to improve bruxism as well as the sleep quality of patients. Clonazepam has anxiolytic, sleep-promoting, mood-stabilizing, and muscle relaxant effects, which makes it a good choice to treat primary and secondary bruxism [14]. The use of clonazepam $0.5 \mathrm{mg}$ in our patient-led to decreased frequency of clenching, however, thispartial improvement might be attributed to a concurrent decrease of sertraline dose.

Our case adds to the evidence that a low dose of quetiapine is a good option for the treatment of antidepressant-related bruxism. Quetiapine

\section{Conclusion}

Management of SSRI-induced bruxism can be challenging. Several medications have been tried with inconclusive results with each agent. Low- dose quetiapine improved our patient's bruxism;

\section{References}

1. Sanchez C, Reines EH, Montgomery SA (2014) A comparative review of escitalopram, paroxetine, and sertraline: Are they all alike? Int Clin Psychopharmacol 29(4): 185-196.

2. Wang SM, Han C, Bahk WM, Lee SJ, Patkar AA, et al. (2018) Addressing the Side Effects of Contemporary Antidepressant Drugs: A Comprehensive Review. Chonnam Med J 54(2): 101.

3. Uvais NA, Sreeraj VS, Sathish Kumar SV (2016) Sertraline induced mandibular dystonia and bruxism. J Family Med Prim care 5(4): 882-884.

4. Ellison JM, Stanziani P (1993) SSRI-associated nocturnal bruxism in four patients. J Clin Psychiatry 54(11): 432-434

5. Wise M (2001) Citalopram-induced bruxism. $\mathrm{Br} \mathrm{J}$ Psychiatry 178: 182.

6. Raveendranathan D, Rao SG (2015) Sertraline induced acute mandibular dystonia. J Neurosci Rural Pract 6(4): 586-587.

7. Paesani DA, Lobbezoo F, Gelos C, Guarda-Nardini L, Ahlberg J, et al. (2013) Correlation between self-reported and clinically based diagnoses of bruxism in temporomandibular disorders patients. J Oral Rehabil 40(11): 803-809.

8. Gill HS, DeVane CL, Risch SC (1997) Extrapyramidal symptoms associated with cyclic antidepressant treatment: A review of the literature and consolidating hypotheses. J ClinPsychopharmacol 17: 377-389.

9. Milanlioglu A (2012) Paroxetine-induced severe sleep bruxism successfully treated with buspirone. Clinics (Sao Paulo) 67(2): 191-192.

10. Çolak Sivri R, Akça ÖF (2016) Buspirone in the Treatment of Fluoxetine-Induced Sleep Bruxism. J Child Adolesc Psychopharmacol 26(8): 762-763.

11. Oulis P, Dimitrakopoulos S, Konstantakopoulos G, Tsaltas was previously shown to be effective in managing bruxism, which may be related to its antagonistic activity on 5-HT2 receptors [12] Quetiapine is a dibenzothiazepine with more potent 5-HT2 than D2 receptor-blocking properties. Because of the fast dissociation of dopamine receptor binding, quetiapine is least likely to induce extrapyramidal symptoms [22]. Indeed, high affinity to block 5-HT2 receptors would theoretically result in less inhibition of the dopaminergic neurons and, hence, less interference with mesocortical tract dopamine release which means that a low dose of quetiapine might be helpful in case of bruxism.

however, it was at the cost of other side effects of quetiapine. Switching from one SRRI to another may be helpful in treating bruxism.

Consent: Consent was obtained from the patient in this report.

E, Kollias K (2012) Low-Dose Aripiprazole in the Treatment of SSRI-Induced Bruxism. J Neuropsychiatry Clin Neurosci 24(3): E39-E39.

12. Zandifar A, Mohammadi MR, Badrfam R (2018) Low-Dose Quetiapine in the Treatment of SSRI-Induced Bruxism and Mandibular Dystonia: Case Series. Iran J Psychiatry 13(3): 227.

13. Grinshpoon A, Weizman A, Amrami-Weizman A (2014) The Beneficial Effect of Trazodone Treatment on Escitalopram-Associated Nocturnal Bruxism. J Clin Psychopharmacol 34(5): 662.

14. Saletu A, Parapatics S, Saletu B, Anderer P, Prause W, et al. On the Pharmacotherapy of Sleep Bruxism: PlaceboControlled Polysomnographic and Psychometric Studies with Clonazepam. Neuropsychobiol 51(4): 214-225.

15. Brown ES, Hong SC (1999) Antidepressant-induced bruxismsuccessfully treated with gabapentin. J Am Dent Assoc 130(10): 1467-1469.

16. Soyata AZ, Oflaz S (2015) Gabapentin Treatment In Bruxism Associated With Fluoxetine. J Clin Psychopharmacol 35(4): 1.

17. Madani AS, Abdollahian E, Khiavi HA, Radvar M Foroughipour M, et al. (2013) The Efficacy of Gabapentin versus Stabilization Splint in Management of Sleep Bruxism. J Prosthodont 22(2): 126-131.

18. Huynh N, Lavigne GJ, Lanfranchi PA, Montplaisir JY, de Champlain J (2006) The Effect of 2 Sympatholytic Medications - Propranolol and Clonidine-On Sleep Bruxism: Experimental Randomized Controlled Studies. Sleep 29(3): 307-316.

19. Garrett AR, Hawley JS (2018) SSRI-associated bruxism Neurol Clin Pract 8(2): 135-141.

20. Sevim S, Kaleağası H, Fidancı H (2015) Sleep bruxism 
possibly triggered by multiple sclerosis attacks and treated successfully with botulinum toxin: report of three cases. Mult Scler Relat Disord 4(5): 403-405.

21. Odabas, FarukÖmer, \&Uca, Ali Ulvi. (2019). The prevalence of bruxism and related factors in patients with multiple sclerosis: a comparative study. Arquivos de Neuro-
Psiquiatria 77(3): 179-183.

22. Caroff SN, Hurford I, Lybrand J, Campbell EC (2011) Movement disorders induced by antipsychotic drugs: implications of the CATIE schizophrenia trial. Neurol Clin 29(1): 127-148 